\title{
DOIS ANIVERSÁRIOS DURANTE A PANDEMIA
}

\section{TWO BIRTHDAYS DURING THE PANDEMIC}

\section{DOS CUMPLEAÑOS DURANTE LA PANDEMIA}

Anamaria Ladeira Pereira ${ }^{1}$

\section{RESUMO}

Sem muito ar, num fôlego só, o deleite-desespero de estar viva, firmando o pé na luta junto a corpos dissidentes, sobrevivendo ao caos pandêmico piorado por um governante que manda a nação às favas. Vontade de meter o pé na porta e barrar os absurdos que vêm sendo perpetrados a cada dia. Ao mesmo tempo, poesia; sopro de velas imaginárias; um feliz aniversário recusado, obrigada. Seguimos respirando, mal nos aguentando em pé às vezes, rodeadas de perdas, ficando mais velhas, mais cansadas e tensas, mais insones, menos resignadas, mais combativas: em pé de guerra com essa história de termos de aceitar caladas.

PALAVRAS-CHAVE: Pandemia. Corpos dissidentes. Lutas.

\section{ABSTRACT}

Almost out of breath, at a stroke, the delight-despair of being alive, steadfast in the struggle with dissident bodies surviving the pandemic chaos worsened by a president who is going to kill us if we don't interrupt him. We need to stop his absurdities, as soon as possible. At the same time, there is poetry here and a blow on the imaginary candles and a happy birthday refused, thanks. We are still breathing, barely standing up at times, surrounded by losses, getting older, more worried and tense. We are also getting more sleepless, less resigned, more combative and extremely exhausted of accepting that we must keep silent.

KEYWORDS: Pandemic. Dissident bodies. Struggles.

\section{RESUMEN}

Casi sin aliento, de un tirón, el deleite-desesperación de estar viva, firme en la lucha con los cuerpos disidentes que sobreviven al caos pandémico agravado por un presidente que nos va a matar si no lo interrumpimos. Hay muchas ganas de detener sus absurdos lo antes posible. Al mismo tiempo, aquí hay poesía, un soplo en velas imaginarias, un feliz cumpleaños rechazado, gracias (a eso fuimos obligadas). Seguimos respirando, a veces malparadas, rodeadas de incontables pérdidas, envejeciendo, más preocupadas y más tensas. También nos estamos volviendo más insomnes, menos resignadas y mucho más combativas: estamos exhaustas de soportar todo calladas.

PALABRAS CLAVE: Pandemia. Cuerpos disidentes. Luchas.

Submetido em: 30/04/2021 - Aceito em: 30/04/2021 - Publicado em: 12/07/2021

1 Mestranda em Educação pela Universidade do Estado do Rio de Janeiro (ProPEd/UERJ). Integrante do grupo de estudos de gênero e sexualidade (geni). Licenciada em Pedagogia pela Universidade Federal do Rio de Janeiro. 
Hoje meus pés completam trinta e sete anos. Esses que já couberam na palma da mão de minha mãe. Esses que atravessaram, por terra ou asfalto, água doce ou salgada, céu turbulento ou tranquilo, arrebatadoras lonjuras e que já se enfiaram em jacas dos mais diversos tipos e meteram-se pelas mãos, em múltiplas ocasiões. Esses que já se pegaram correndo, como se asas minúsculas lhes saíssem pelos tornozelos, em espaços quadrados onde os corredores, mesmo com nome tão sugestivo, devem ser percorridos com calma: "nada de correria, assim você cai". Esses pés, hoje, não se arredam de tacos de madeira antigos cobertos de verniz, mas imaginam musgos e grama e areia molhada de mar, pressentindo as cócegas.

Pés de moleca que já andaram aparentemente sem rumo, escalando sonhos só para se deparar com penhascos e para se emaranhar em outros pés, nas incontáveis danças nas quais inventaram de entrar. Outrora, esses pés de valsa foram suturados e engessados, numa infância da pá virada, semente da idade adulta na qual o chão de casa é a única estrada por quase um mês. O mês mais parado em trinta e sete anos, parece. Por dentro, contudo, esses pés se mexem de um tanto, feito balanço de parque os habitasse. Minha festa é estar viva - diz o pedaço de raiz a brotar das plantas movediças - meu presente é ter experimentado até aqui a vida mais intensa que pude.

Trinta e sete outonos e vontade incessante de aprender e criar e me apaixonar muitas mais vezes; também de recuperar o que perdi injustamente; embora, ao ser roubada, tenha me livrado daquele capítulo atrás das grades de horários e chamadas e abundantes mediocridades. Meus pés se arrastam em chinelos nesses agoras, mas é forró pé de serra. A quarentena se mantém embalada por música ao vivo, pois a banda mora comigo e meu par eu carrego no colo. Aperto na palma da mão seus pezinhos e penso nos inúmeros sendeiros que esses pequeninos vão desbravar.

Torço para a parte dos gessos e costuras ficar só nas histórias da tia-e-madrinha, esta que escreve ao pé da letra e conta ao pé do ouvido e que morde mas não lambe pés, no caso botas, e faz rir até brotarem pés de galinha. Meus pés adentram o novo ano de vivências, em parte pé ante pé: esse tempo requer cuidado desacelerado; em parte com pé atrás, ressabiados; em parte já caindo de amores, porque são desses: de sapatos de palhaça, prontos para colher frutos em pés de amora sem pé nem cabeça. Peito miúdo demais para tanta danação imensa. Espero menos péssimas tramas e mais pétalas nas veredas abertas por onde a base do corpo vai trilhar, e um encontro que dê pé, que dê flor e dê substância com a qual se lambuzar até os dedos que passeiam, digo, passeavam, em sandálias sem saltos, e têm vivido descalços, gestando uma falta aguda de cada pessoa amada. 


\section{1.}

Era menos de uma lua inteira e já parecia a eternidade. Meus trinta e oito anos chegaram sem beijos estalados. Hoje. Trinta e oito velas inexistentes em cima de um bolo imaginário. Fиииии (é o barulho de um sopro inaudível). Completo este aniversário com raiva. E não é pouca. Três oitão, disse-me Lygia Fernandes sobre a nossa idade, e quanta ironia esse nome de metal que atira, Lygia... logo eu, tão desarmada; com a saudade nos braços, parida prematura, filha do isolamento, que me suga ou uiva esgoelada. No último-meu-dia, o fim do caos parecia logo ali na volta da esquina. A gente mal começava a tapar metade da cara, evitava sair de casa (se possível) e contava nos dedos os dias sem afagos. De repente: inacabáveis meses, angústia perene, durou e dura. A maciez dos giros com aquelas moças, no Armazém do Campo do MST, lembrança doída. Última farra só podia ter sido no meu recanto favorito no Rio.

Completo anos, neste 2021, bem séria, após o coronavírus fazer uma translação completa, dentro da Terra, ao redor do Sol, espectador abismado da tragédia na qual estamos submergindo. Cadê que cabe festa no meio disso? Cancelo a live, é difícil achar tão lindo estar viva, um ano depois, nesse mar de gente que deixou de existir, podendo ainda estar vivinha da silva; suas histórias receberam um ponto final à revelia. Pessoas pobres, negras, indígenas e mulheres, ao redor do mundo, mesmo em países ricos, são as mais atingidas, apontam Angela Davis e Naomi Klein. Para as LGBTI+ também aumentou o perrengue.

Pelas bandas de cá, um celerado, adorador da supremacia branca, desincentiva a vacina: "Se você virar um jacaré, é problema seu". Também ouvi, à beça, na minha infância: "mulher com mulher dá jacaré". Mania de usar o réptil verde assustador para amedrontar a gente de se livrar do que tanto queremos nos ver livres. Mulher com mulher dá parceria das mais incríveis, isso sim. Expulsaram a presidenta, convictos de que "pedaladas físcais" são graves, gravíssimas; o extermínio de quase meio milhão de vidas não é suficiente para interditar um mandato.

Privilégio seguir respirando e imune ao vírus, escreveu Debora Diniz, quando sequer há um plano nacional de combate. Seguro a boca e impeço o grito. Tampo os ouvidos para que "Parabéns!" algum me alcance. Do lado do avesso, há um toró salgado que custa a cessar. Como disse Conceição Evaristo: essa pandemia me pegou por dentro, sabe? Do lado de fora, as sobrancelhas se aproximam, os olhos lutam para permanecer secos. Tem gente com fome, tem gente sem ar, tem gente sendo envenenada com remédios inúteis. $O$ brasileiro na função mais alta do Executivo pensa que é um rei e a nação que se lasque. Como se monarcas sanguinários ("só Deus me tira daqui", diziam) não tivessem sido destituídos do cetro e majestade, por mãos humanas oprimidas e contundentes: Basta! Contra esse que ameaça processar quem o chama de genocida, enquanto deixa morrer à míngua parte considerável da 
população, é preciso muita, mas muita gente mesmo, gritando junta, em praça pública: "Fora! Tudo tem limite".

Quero este presente para as minhas trinta e oito reviravoltas: desembrulhar um Brasil bem alimentado, e não faminto, disposto a dar um pé na bunda em quem debocha das atrocidades causadas por suas próprias ações. Genocídio, aliás, combina com "desejo alegrias, feliz aniversário"? Numa pandemia descontrolada, muito obrigada, dispenso as felicidades, as celebrações, tudo o mais deveras incompatível com as máscaras. Aceito, porém, de bom grado, bater o pé coletivamente, pisar firme, pisar ligeiro, até que venha um pé de vento, ventania benfazeja arretada, e afaste o pequi roído do cargo.

Aí a gente festeja.

\section{REFERÊNCIAS}

DAVIS, Angela; KLEIN, Naomi. Construindo movimentos: uma conversa em tempos de pandemia. São Paulo: Boitempo, 2020.

DINIZ, Debora. Crônica do imunoprivilégio. El País. Disponível em:

<https://brasil.elpais.com/opiniao/2021-04-23/cronica-do-imunoprivilegio.html>. Acesso em: 26 abr. 2021.

JUCÁ, Beatriz. Chip na vacina, "virar jacaré” e outros mitos criam pandemia de desinformação na luta contra a covid-19. El País. Disponível em:

$<$ https://brasil.elpais.com/brasil/2020-12-20/chip-na-vacina-virar-jacare-e-outros-mitoscriam-pandemia-de-desinformacao-na-luta-contra-a-covid-19.html>. Acesso em: 26 abr. 2021.

SANTANA, Tayrine; ZAPPAROLI, Alecsandra. Conceição Evaristo "a escrevivência serve também para as pessoas pensarem". Itaú Social. Disponível em:

$<w w w . i t a u s o c i a l . o r g . b r / n o t i c i a s / c o n c e i c a o-e v a r i s t o-a-e s c r e v i v e n c i a-s e r v e-t a m b e m-p a r a-a s-$ pessoas-pensarem/>. Acesso em 26 abr. 2021.

Este é um artigo de acesso aberto distribuído sob os termos da Licença Creative Commons Atribuição Não Comercial-Compartilha Igual (CC BYNC- 4.0), que permite uso, distribuição e reprodução para fins não comerciais, com a citação dos autores e da fonte original e sob a mesma licença. 